\section{Implementation of injury prevention for children and young people}

\author{
Elizabeth Towner, Yvonne Carter, Michael Hayes
}

A 1996 World Health Organisation report, Investing in Health Research and Development, warns that worldwide, "the epidemic of injuries may be among the most neglected health problems of the late 20th century". "We see evidence of this neglect in investment in injury research, and in the paucity of evaluated studies on injury prevention for children and young people. More neglected still, is a concerted attempt to implement established interventions at national and local levels throughout the UK.

The path to implementation is broken too often. In this chapter we explore the barriers and opportunities in the UK for implementing injury prevention for this age group in a more widespread and systematic manner. We first examine the picture of injury prevention at national and local levels. This leads to the conclusion that there would be significant benefits from having national lead agencies for this problem along with improved local coordination. To this end we look at:

- Strategy development at national and local levels.

- Capacity building.

- Methods to bridge the gap between research and practice.

- Multiagency or health alliances.

- The need for good data.

Three examples are then presented. The first examines the scope for injury prevention in the primary health care setting. It focuses on an individual approach to children, young people and their families, and represents a possible opportunity for health promotion. The other examples both involve multiagency approaches. Example two is a multiagency programme to promote cycle helmet use. Example three documents the use of a Safe Community approach.

General Practice and primary care, Queen Mary and Westfield College, London Y Carter

Child Accident Prevention Trust, London $M$ Hayes

Correspondence to: Community Child Health, Donald Court House, 13

Walker Terrace, Gateshead NE8 1EB (e-mail:

e.1.m.towner@ncl.ac.uk). National injury prevention in the UK In the UK, no single agency or profession "owns" the prevention of unintentional injuries to children and young people, either at national government or local levels. This can lead, at worst, to a failure to act, or at best to a lack of coordination or duplication of effort. While there may be a lack of clarity about ownership, there is no lack of involvement in the subject at certain levels.

Nationally, many government departments and other bodies are involved in attempts to Dr Elizabeth Towner, prevent those injuries (table 1). The involvement of the departments, etc, shown in this table ranges from policy formulation, commissioning of research, undertaking and/or commissioning educational and publicity campaigns, developing and enforcing regulations, implementing engineering measures, collecting and disseminating information (including statistics), and liaising with international bodies, especially those within the European Union.

Within Scotland, Wales, and Northern Ireland, the responsibilities outlined in table 1 will reside with the relevant sections of the Scottish Office, Welsh Office, and Northern Ireland Office, respectively.

In addition, there are many nongovernmental organisations active in this field, including the Child Accident Prevention Trust and the Royal Society for the Prevention of Accidents.

The benefit of action being taken at national level is that it applies to children and young people throughout the country equally, although the degree to which policies are implemented may vary from one locality to another depending on local resources.

\section{Local injury prevention}

There is a similar multiplicity of agency involvement at the local level, primarily comprising local government, health sector departments, voluntary and community groups (table 2). However, in very few cases, is accident and injury prevention the mainstream function of any of these agencies.

The few studies that have been carried out show that local injury prevention activities often lack a sound scientific basis, are weakly evaluated, or fail to make use of expert advice. $^{2-4}$

A 1994 review of child accident prevention activities among local government, voluntary sector, health service, and emergency services in Scotland ${ }^{2}$ found that many disciplines and agencies were involved to varying degrees. In road, home and leisure safety, limited evaluation seemed to be taking place and where evaluation did occur it concentrated on process, rather than outcome measures.

Another survey, conducted with 30 purchaser authorities in the south and west of England, painted a similar picture. This revealed considerable multiagency activity in 
Table 1 Selected government departments and agencies with an involvement in accident and injury prevention

\begin{tabular}{ll}
\hline $\begin{array}{l}\text { Type or location of accident or } \\
\text { injury }\end{array}$ & Government department or agency \\
\hline Road & Department of the Environment, Transport and the Regions \\
Home design and construction & Department of the Environment, Transport and the Regions \\
Domestic products & Department of Trade and Industry \\
Pharmaceuticals & Department of Health \\
Treatment & Department of Health, NHS Executive \\
Occupational & Health and Safety Executive, Department of Health \\
Schools & Department for Education and Employment \\
Sport, play, and leisure & Department of Culture and National Heritage \\
Fires & Home Office \\
Drowning & Department of the Environment, Transport and the Regions, Department of Trade and Industry \\
Child care facilities & Department of Health \\
\hline
\end{tabular}

the area of injury prevention, but identified a number of weaknesses:

"Child accident prevention strategies are frequently of poor quality and generally do not recommend action in sufficient detail either by agency responsibility or intervention type. Collaboration in strategy formulation by alliance partners is also infrequent". ${ }^{3}$

This survey also demonstrated that research evidence had little influence on the preventive practices: most of the reported interventions related to education or parental counselling, with few targeting environmental changes.

A second English study of health alliances, related to child safety in 18 English counties, reflected the Scottish survey in that there was little attention paid to evaluation. In only one area had the multiagency group had access to specialist advice and assistance on evaluation, in this case a Health of the Nation monitoring office. Few groups had full time staff to support the multiagency group and there was little evidence that work at the local level was informed by local injury data. ${ }^{4}$

The conclusions drawn in the United States in 1985 by Micik and Miclette appear to be equally applicable to the UK in recent years:

"Most injury prevention efforts are scattered and uncoordinated, resulting in little impact on the overall incidence and outcome of injuries". ${ }^{5}$

Need for national and local lead agencies

The diversity of national departmental and professional involvement points to the need for a single national agency, in each of the four countries, being designated to take the policy, implementation, and research lead on this subject. Such national injury prevention and control agencies could result in:

- Injury prevention being researched holistically.

Table 2 Local involvement in the prevention of accidents and injuries

\begin{tabular}{lll}
\hline $\begin{array}{l}\text { Local government } \\
\text { departments and agencies }\end{array}$ & Health sector departments and staff & $\begin{array}{l}\text { Voluntary and community } \\
\text { organisations }\end{array}$ \\
\hline $\begin{array}{l}\text { Education } \\
\text { Environmental health }\end{array}$ & Accident and emergency & Campaign groups \\
Fire service & Communce service & Child care and play organisations \\
Highways & School nursing & Tenants associations \\
Home safety & Public health & Uniformed organisations \\
Housing & General practice & \\
Parks and leisure services & Health promotion and education & \\
Road safety & Health visiting & \\
Social services & Nursing & \\
Trading standards & Pharmacy & \\
Transportation & & \\
\hline
\end{tabular}

- Injury prevention being implemented in an integrated manner rather than sectorally at present.

- Expertise, much of which applies in each of the specialist prevention areas (road, home, leisure, etc), being more accessible to national and local practitioners.

- Coordination of funding.

- The development of a comprehensive information centre.

- A focus for the media, with a consequential raising of the public profile of the subject.

- The development of a national training centres.

- Improved coordination of data systems.

The major example of a national lead agency in this field is found in the United States where the National Center for Injury Prevention and Control at the Centers for Disease Control and Prevention coordinates prevention activity and research. The publication of Injury in America ${ }^{6}$ is regarded as having led to the establishment of this centre.

Locally, the subject would benefit from there being a single department, probably within the public health section of the health authority, coordinating health and local authority policy and action. This may be achieved through recent government initiatives to introduce health improvement programmes.

\section{Strategy development in the UK}

Government health strategies such as The Health of the Nation, Our Healthier Nation, and the equivalent Scottish, Welsh, and Northern Irish strategies have been positive moves towards defining the key role of the health sector in the injury field. ${ }^{7-13}$ They have advocated better interdepartmental coordination of initiatives and defined more clearly the leadership role of the health sector for injury prevention as a whole.

These strategies have included targets for death and injury rate reductions and the definition of indicators for measuring progress. Such targets and indicators can:

- Demonstrate a commitment and the need for action.

- Provide a national framework under which local action can be undertaken, thus enabling local agencies to identify more closely with the aims of national programmes.

- Provide guidance on how to use resources most effectively. 
- Set out numerical and process measures that can be used nationally and locally that are not reliant on death and injury data.

The definition of detailed objectives for the prevention of general and specific unintentional injury topics has been used extensively by the Australian government, set out in Better Health Outcomes for Australians. National goals, targets and strategies for better health outcomes into the next century. ${ }^{14}$ In England, a similar document has been drafted, focusing specifically on injuries to children and adolescents and the infrastructure needed to implement the prevention process. ${ }^{15}$

A key opportunity for local injury prevention action is created through the health improvement programmes arising from the white paper, The New NHS: Modern and Dependable. ${ }^{16}$ Local health services have to develop strategies in conjunction with local councils for improving the health of their population. Health authorities will also be expected to work in partnership with other organisations to improve health and reduce inequalities. The green paper, Our Healthier Nation, ${ }^{8}$ brings together all of the government's previous policy decisions relating to public health. It proposes a national contract for better health, with accidents being one of four priority areas highlighted for action. A new national performance framework will be used to measure progress against national targets. These changes will set a new framework that will allow increased development of injury prevention in local communities.

A second initiative arising from Our Healthier Nation $^{8}$ that should benefit local injury prevention is the development of healthy living centres. These may provide a local centre from which action can derive and create the opportunity to highlight the importance of the subject, especially in the areas of greatest need.

One of the benefits of the 1992 England health strategy, The Health of the Nation, ${ }^{7}$ was its creation of a new local resource for injury prevention work arising from the definition of priorities. The level of resource made available ranged from the addition to a person's job description of responsibility for accident and injury prevention to new injury prevention coordinator posts. Regrettably these important posts were often short term and many have subsequently disappeared.

A common activity of local multiagency groups has been the development of local policy statements to which the key local government and health departments were able to sign up. While in some cases, these policy statements were not innovative, only reflecting the aims of current activities, they nevertheless were statements of intent and recognition of the importance of the subject.

\section{Capacity building}

To address injury prevention for children and young people nationally and locally in the UK, a well trained, highly motivated workforce is essential. Thus training in injury prevention is needed for professionals and policy makers at the national level, and for practitioners, such as injury prevention coordinators, at the local level. The implementation of Australia's $\mathrm{Na}$ tional Better Health Programme provides evidence that many short term injury prevention projects were not sustained and institutionalised because there was a lack of people with the experience needed. ${ }^{17}$ This partly relates to lack of training, but it is also a reflection of a lack of job security for researchers and practitioners in this field. Moller's comments on the Australian situation is equally applicable in the UK: "It is unusual to see a field of endeavour that is a nominated public health priority where the field itself is in a state of constant insecurity". ${ }^{18}$

A review of the literature reveals relatively few interventions that have specifically targeted the training of professionals, lay people, or policy makers. But there are glimpses that these approaches can be successful, as demonstrated in the Falköping community based injury prevention programme in Sweden. ${ }^{19}$ The Safe Block community based programme in Philadelphia successfully used cascade training to inform and involve community representatives. ${ }^{20}$ Similarly, in Glasgow, local people were involved in training programmes for children. ${ }^{21}$ These interventions have been discussed in section 2 . Training health professionals in child care centres in the United States in issues relating to car occupant injuries resulted in a change in the culture of these centres. One result was the introduction of formal "contracts" being established with parents regarding the safe transportation of their children in cars. ${ }^{22}$

The content of training courses is important; it can range from education about principles and concepts that lead to an increase in knowledge and understanding, to the acquisition of competencies. These might include competencies in group work, community development, multisectoral collaboration, or lobbying. ${ }^{23}$ From outside the injury field, the Stanford Five-City Project used a capacity building approach to develop competencies in a core group of local health educators, enabling those educators to sustain local programmes. ${ }^{24}$

To assess training needs in injury prevention, what is required is the establishment of advisory groups (subgroups of the national injury prevention and control agencies suggested earlier in the chapter). Funding is also needed to establish training courses and for the production of materials.

The Monash University Accident Research Centre's short course and accompanying text Injury Research and Prevention: A Text provide useful models. ${ }^{25}$ The United States, Injury Prevention: Meeting the Challenge has been widely used to introduce workers to the topic of injury prevention. ${ }^{26} \mathrm{~A}$ book directed at practitioners Community Based Injury Prevention: A Practical Guide, documents 10 community based projects in Australia. ${ }^{27}$ This provides insights into what works and does not work at a local level.

\section{Methods to bridge the gap between research and practice}

Injury prevention, in common with other areas of health promotion, has difficulties applying 
lessons learned from research and improving the "fit" between research and practice. ${ }^{16}$ Improved training for practitioners can facilitate this process. What is also required is improved communication between researchers, health managers, and practitioners. All too often the communication is one way; less frequent is there, "a true dialogue between researcher and practitioner where the information flow is two way, with researchers taking back messages from practitioners concerning the relevance and practical application of their research activity". ${ }^{28}$

\section{Multiagency or health alliance approaches}

In response to the severity and complexity of chronic health problems, health promotion in recent years has stressed the importance of multiple interventions at a number of different levels. The multiagency or healthy alliance approach has been developed as one strategy to coordinate a range of interventions. Such a coordinated approach is appropriate for injury prevention. Pless believes that one of the reasons why little information on effectiveness is used to its best advantage is the fact that many of the potential participants only play "bit roles" and there is too little coordinated activity. ${ }^{29}$

Many of the ways of preventing accidents and injuries lie within the remit of different departments of local government (for example road safety, leisure services). The health services, however, have an important role in providing injury data and employ staff who are in a position to provide health education (health visitors, school nurses, health promotion officers, general practitioners (GPs)) and who can highlight issues in directors of public health annual reports. Voluntary agencies, industry, and commerce also have a role. There are numerous advantages of multiagency working but, in practice, there also are disadvantages.

The advantages are that organisations can be involved in injury prevention issues without having the sole responsibility for them; duplication of effort and services can be minimised; resources such as information, skills, and finance can be effectively used; and data collection improved. Collaboration can benefit from the sharing of information. If barriers between agencies are broken, a synergistic effect can be obtained. Potential disadvantages of multiagency working include conflicts between different member organisations and their professional roles, problems in group dynamics, frequent turnover of representatives, poor planning by the lead agency, and poor use of scarce time and financial resources. Above all there is a lack of leadership and responsibility. ${ }^{4}$

Research in the UK has shown that multiagency working in injury prevention is often informal and that there is a lack of commitment for multiagency working within management systems. ${ }^{30}$ Work in other countries has demonstrated that studies using a multiagency approach have produced reductions in accidents and injuries. ${ }^{31}$

In order for a multiagency injury prevention group to work well, it needs to have status and recognition within the management hierarchy of the bodies that the individuals represent. It also needs to have continuity of membership, strong leadership, clarity of purpose, and an understanding of the values, approaches, responsibilities, and opportunities of its constituent bodies. Having a funded coordinator to service the group, the involvement of senior management on strategic multiagency groups, and a culture within the relevant agencies that encourages flexible working also contribute to success. Funding dedicated to multiagency working is essential to fuel this process.

\section{Need for good data}

Injury surveillance systems have a key role in the prevention of childhood injury and such data are needed at both national and local levels. "Injury data can confirm, disprove, or refine an analysis of an injury problem and are essential for the design, implementation, and evaluation of an effective injury prevention and control program" ${ }^{26}$ Two reviews of data sources in the UK have been conducted. ${ }^{32}{ }^{33}$ The systems have been developed by different agencies, commissioned at different times and for different purposes "None of the systems allows a complete picture to be seen of the scale and profile of accidents to children". ${ }^{32}$ In addition, many of the systems have little relationship with one another.

Evidence from community based studies at a local level show the benefits of good local surveillance systems, "both for generating the development of a community-based and locally relevant injury prevention program and for evaluating the impact of such a program". ${ }^{34}$ Thus local priorities can be identified and improved targeting can take place. Schelp points out another important function of local data in educating policy makers and the public about the magnitude of the injury problem. "Local injury data are necessary to gain the support of local authorities, organisations and the population, who may not believe that these problems exist in their community". ${ }^{19}$

But the situation with regard to injury data is also far from ideal at a local level in the UK. Surveys of multiagency injury prevention groups, referred to earlier in this chapter, found little evidence that local preventive work was informed by local injury data. ${ }^{2-4}$ Only in the road safety field were data (STATS19 data collected routinely by the police) applied to local problems. Deficiencies in data systems in relation to event location and characteristics are extensive and must be addressed as a priority.

Methodological support for the development of local data initiatives is essential. Such a strategy needs direction. Advisory groups (subgroups of the national injury prevention and control agencies as suggested earlier in the chapter) are needed to develop data systems where data of sufficient detail and quality are collected to identify injury mechanisms and to monitor trends over time. 
Examples of settings and approaches

EXAMPLE 1-THE PRIMARY CARE SETTING

In the UK, the GP's increasing role in health promotion was emphasised in both the government's consultative paper on the future of primary care services ${ }^{35}$ and in the Royal College of General Practitioners' response. ${ }^{36}$ The Health of the Nation. Key Area Handbook ${ }^{37}$ on accidents supported the view that some accident prevention activities are the responsibility of primary care.

Unintentional injuries, particularly to preschool children, are a significant cause of morbidity in primary care. Both GPs and health visitors are in regular contact with families with preschool children and are thus well placed to undertake an important role in educating parents and providing information that is directly relevant to them. ${ }^{38-42}$ They see families in planned regular encounters, such as routine health checks, and in unplanned meetings, such as after an accident. Previous studies have aimed to assess the role of family doctors, ${ }^{43-46}$ paediatricians, ${ }^{47}$ health visitors, ${ }^{48-50}$ and teachers $^{51}$ in the prevention and treatment of unintentional childhood injuries. There is still a need, however, for further evaluation of the role of professionals in injury prevention.

The evidence suggests that many UK family doctors are in favour of initiating discussions with parents on injury prevention at varied times and locations. ${ }^{46}$ However, although the majority of respondents in the survey by Carter et al considered injury prevention to be part of their role, only $28 \%$ felt that they had sufficient input in this area. Lack of time was cited as the most significant limiting factor. Child health surveillance clinics and during treatment of an accident were considered the most appropriate times for members of the primary health care team (PHCT) to give prevention advice. These findings support the suggestions made in an earlier discussion paper by Kendrick. ${ }^{52}$ In the course of their home visits, GPs and health visitors may also be able to point out hazardous practices or dangerous features of the home. Accident-prone families, or those vulnerable from stress or illness, may be highlighted in the case notes and in "parent held" personal child health records. Although a report from the Audit Commission ${ }^{53}$ emphasised the need to enhance the use of parent held records, the number of respondents in the survey of Carter et al who made use of these records in accident prevention work was, however, surprisingly low.

In general, the suggestion that GPs and their teams should adopt a public health role and take responsibility for monitoring accidents has aroused little enthusiasm. ${ }^{54}$ The difficulty of surveillance in general practice is compounded by the fact that children who have accidents are often taken directly to hospital accident and emergency departments. ${ }^{45}$ Prospective accident data collection in general practice may be easier than retrospective record searching as previous work has suggested that details of accidents are often recorded inadequately. ${ }^{55}$ Nevertheless, despite the recent high level of computerisation in primary care, the number of practices prospectively recording accident details onto a computer and using childhood injury prevention as a topic for auditing practice based activities is disappointing. ${ }^{46}$

The scope for child injury prevention within the primary care setting is enormous and feasible if it is incorporated into existing activities. Towner has emphasised the importance of educating professionals to prepare them for this role and to alert them to the wider social issue of making the environment safer. ${ }^{56}$ However, training is an area that has previously been addressed only for health visitors. ${ }^{57}$ The Child Accident Prevention Trust training resource for health visitors stressed not only work with individual families, but also work at a community level, for example by supporting local groups in campaigning for safer environments. Despite wide use and dissemination of the resource, formal evaluation of its effect has not taken place. Cody and Waine describe how they used this training programme, along with local statistics, as the basis for a workshop to increase health care workers' awareness of the need to target specific childhood accidents. ${ }^{58}$

A national survey found that only $10 \%$ of GP respondents had attended a course or lecture on accident prevention in the last two years. ${ }^{46}$ Doctors from fund holding practices were more likely to have done so. A larger proportion $(16 \%)$ reported that other members of their PHCT had attended such training. An earlier district based survey in North Staffordshire found that only $43 \%$ of GPs felt that they had enough background information on injury prevention. ${ }^{45}$ There is little information on the availability and uptake of courses on child injury prevention, particularly for doctors.

In 1995 Phalp conducted a study on behalf of the Child Accident Prevention Trust to assess the opportunities and needs of PHCTs in London to undertake injury prevention. ${ }^{59}$ Not unexpectedly, he found that apart from health visitors, the staff had had little training and were only involved in a minimum level of prevention activity. Phalp recommended that acceptable training for primary care staff should be more available and suggested that relevant information about injury rates and local initiatives should be included in such training.

Work from America supports the view that an injury prevention programme can easily be incorporated into primary care paediatric settings. ${ }^{60}$ The Injury Prevention Program (TIPP) developed by the American Academy of Pediatrics, provides a detailed set of guidelines and materials to help physicians implement injury prevention counselling. ${ }^{61}$ The TIPP programme has been used extensively in the United States and has been evaluated for acceptability in its office use. ${ }^{62}$

Professional associations and colleges also have an important part to play through postgraduate examinations and the development of courses. Guidelines that span primary and hospital based care should have input from both generalists and specialists. Increasing clinicians' participation in intervention trials may be another way to improve the uptake of 
their findings. Professional bodies may also influence the public. An advocacy role could be applied to childhood injury through the involvement of the Royal College of General Practitioners with the Royal College of Paediatrics and Child Health and the Faculty of Public Health Medicine in the present Action on Injury initiative.

EXAMPLE 2- A LOCAL MULTIAGENCY PROGRAMME TO PROMOTE CYCLE HELMET USE Research in Australia and the United States has demonstrated that cycle helmets are associated with reduced severity of head injuries ${ }^{63}{ }^{64}$ and that mandatory helmet wearing laws increase helmet wearing rates in Australia. ${ }^{65}$ Helmet wearing can also be increased through voluntary means, even with teenagers, especially when hospitals take the lead in helmet promotion, as work in Reading has demonstrated. ${ }^{66}$

The programme in Reading involved a number of agencies and collaborators:

- It is led by a specialist paediatric nurse who has first hand experience of caring for head injured children.

- Data for programme definition and evaluation has been provided by the accident and emergency department of the local hospital.

- The cost benefits of the programme have been evaluated by the commercial manager of the hospital, thus persuading the hospital trust board to provide support.

- Local schools have provided access to the nurse to enable her to talk to children about head injuries and their prevention, work with them to prepare programme material and carry out research into attitudes and knowledge.

- The local newspaper and television station have given consistent publicity to the programme.

- The hospital has sold cycle helmets at cost price.

- A consultant paediatrician has collaborated in evaluative research and the dissemination of the results through the coauthoring of a journal paper and the presentation of the programme to national conferences.

- The local member of parliament has assisted in seeking government funding for the expansion of the programme to other parts of the UK.

- Local businesses have provided support for the expansion of the scheme and the establishment of a charity to run it nationally.

In summary, the important features of this programme are a sound basis in research, a clear aim, multiagency and multiprofessional involvement, accessible timely data, a well structured controlled evaluation and a planned dissemination strategy.

EXAMPLE 3-A MULTIAGENCY SAFE COMMUNITY STRATEGY

The Safe Community strategy developed in Sweden in the 1970s has been applied to child safety issues in the small town of Penarth in South Wales. Process evaluation of Safe Child Penarth has been conducted by the University of Wales, College of Medicine, to see whether the programme has met the 12 criteria for the Safe Community network. ${ }^{67}$

Important elements of the initiative in Penarth include:

- The project was jointly initiated by the health authority and town council.

- Funding was provided (mostly by the health authority) for a half time project coordinator and secretary.

- A multiagency steering committee was coopted.

- Good data on childhood injury were available from the local accident and emergency department.

- The local data informed the development of a safety agenda.

- The project was evaluated by the local university.

- Qualitative methods were used, such as focus groups with socially disadvantaged parents.

Although the programme obtained good support from statutory agencies, it found community involvement to be more problematic. Nevertheless, over the two year period 10 out of the 12 criteria for the Safe Community network were achieved. ${ }^{67}$

\section{Conclusions and recommendations}

The wide diversity of responsibility and opportunity for preventing accidents and injuries to children and young people means that without efficient networking and/or collaboration within management structures and procedures, there is a serious risk we will continue to undertake prevention work inefficiently. The implementation of research findings deserves greater attention and serious commitment.

In summary, we recommend that government demonstrate commitment to the injury prevention issue, improve coordination both nationally and locally, and promote evidence based policy.

DEMONSTRATE COMMITMENT

- There is a need for greater national commitment to injury prevention, capitalising on the opportunities offered by government initiatives.

- Capacity building in the field of injury prevention is required for policy makers and practitioners. This includes the development of training courses and materials. Professional associations and colleges have a part to play through postgraduate examinations and the development of courses.

- Funds must be allocated to these areas on a continuing basis as essential components of a long term strategy.

IMPROVE COORDINATION

- There is a need in each of the countries for single national agencies (National Injury Prevention and Control Agencies) to take the lead to coordinate an injury prevention strategy and programme. Similarly, at the local level, coordination of policy develop- 
ment and action should reside within a single lead agency.

- A multiagency approach is essential. This requires commitment and resources to make it work.

PROMOTE EVIDENCE BASED POLICY

- Policy decisions must be based on the most up-to-date and rigorous research evidence. Therefore, a strategy must be developed to improve communication between researchers and practitioners and disseminate results and information.

- The implementation of research in a widespread manner has been little documented in the past. There is a need for this area to be researched and funded in its own right (see previous comments).

- New and existing injury prevention programmes should be evaluated in a rigorous manner, and should include outcome evaluation methods. There may be a role for a national consultative body for designing such evaluations.

- Good local data on childhood injury can help to stimulate injury prevention and tailor it to local circumstances. Therefore local injury data surveillance should be encouraged and supported.

1 World Health Organisation. Investing in health research and development: report of the Ad Hoc Committee on health research development: report of the Ad Hoc Committee on health research

2 relating to future intervention options. Geneva: WHO, 1996. tion in Scotland. Main findings. University of Strathclyde, Centre for Social Marketing, 1994

3 Speller V, Mulligan J, Law C, et al. Preventing injury in children and young people. A review of the literature and current practice. Winchester: Wessex Institute of Public Health Medicine, 1995.

4 Child Accident Prevention Trust, Health Education Authority. Evaluation of a child accident prevention through healthy alliance interventions. Final research report. London: CAPT, 1995.

5 Micik S, Miclette M. Injury prevention in the community: a systems approach. Pediatr Clin North Am 1985;32:251-65.

6 Committee on Trauma Research, Commission on Life Sciences, National Research Council and Institute of Medicine. Injury in America: a continuing public health problem. cine. Injury in America: a continumg public health

7 Department of Health. The health of the nation. A strategy for health in England. London: HMSO, 1992.

8 Secretary of State for Health. Our healthier nation. A contract for health. London: The Stationery Office, 1998.

9 Department of Health and Social Services Northern Ireland. Wellbeing into 2000: a positive change for health and wellbeing. Belfast: Strategic Planning Branch, DHSS Northern Ireland, 1996.

10 Department of Health and Social Services Northern Ireland. Health and wellbeing into the next millennium. Belfast: Strategic Planning Branch, DHSS Northern Ireland, 1997

11 Health Promotion Authority for Wales. Health for all in Wales: plans for action. Cardiff: HPAW, 1992.

12 Scottish Office Department of Health. Working together for a healthier Scotland: a consultation document. Edinburgh: The healthier Scotland: a consult

13 Welsh Office/Welsh Health Common Services Agency. Protocols for health gain: injuries. Cardiff: Welsh Office, 1991.

14 Commonwealth Department of Human Services and Health. Better health outcomes for Australians. National goals, targets and strategies for better health outcomes into the next century. Canberra: Australian Government Publishing Service, 1994.

15 Hayes M, Towner E. Reducing unintentional injuries to children under 15 years old in England. Setting objectives and plans for the period 1998-2010. Discussion document prepared for the Department of Health, 1998.

16 Secretary of State for Health. The new NHS: modern and dependable. London: HMSO, 1997.

17 Albany P, Kreisfeld R. Injury prevention and control in Australia A review of current programs and activities. Canberra: Australian Government Publishing Service, 1994

18 Moller J. Injury prevention and control: gaps and opportunities. Unpublished discussion paper, 1996.

19 Schelp L. The role of organizations in community participation - prevention of accidental injuries in a rural Swedish municipality. Soc Sci Med 1988;26:1087-93.
20 Schwarz DF, Grisso JA, Miles C, et al. An injury prevention program in an urban African-American community. Am $\mathcal{F}$ Public Health 1993;83:675-80.

21 Thomson JA, Whelan KM. A community approach to road safety education using practical training methods. The Drumchapel project. Road safety research report No 3. London: Department of Transport, 1997.

22 Stuy M, Green M, Doll J. Child care centers: a community resource for injury prevention. 7 Dev Behav Pediatr 1993;14:224-9.

23 Latter S. Nursing, health education and health promotion: lessons learned, progress made and challenges ahead [editorial]. Health Education Research 1998;13(2):i-v.

24 Jackson C, Fortmann SP, Flora JA, et al. The capacity building approach to intervention maintenance implemented by ing approach to intervention maintenance implemented by 1994;9:385-96.

25 Ozanne-Smith J, Williams $\mathrm{F}$, eds. Injury research and prevention: a text. Victoria, Australia: Monash University Accident Research Centre, 1995.

26 National Committee for Injury Prevention and Control. Injury prevention: meeting the challenge. New York: Oxford University Press, 1989

27 National Safety Council of Australia. Community based injury prevention. A practical guide. South Australia: National Safety Council of Australia, 1992.

28 Nutbeam D. Achieving "best practice" in health promotion: improving the fit between research and practice. Health Education Research 1996;11:317-26.

29 Pless IB. The scientific basis of childhood injury prevention. A review of the medical literature. London: Child Accident Prevention Trust, 1993

30 Child Accident Prevention Trust. Approaches to local child accident prevention project (ALCAPP). London: CAPT, 1991.

31 Ozanne-Smith J, Sherrard J, Brumen IA, et al. Community based injury prevention evaluation report: Shire of Bulla safe living program. Report No 66. Melbourne: Monash University Accident Research Centre, 1994.

32 Benson A. The collection and dissemination of accident data. Discussion paper. London: Child Accident Prevention Trust and Faculty of Public Health Medicine, 1993.

33 Department of Health. Public health information strategy. Implementation project 19. Improving information on accidents. London: Department of Health, 1993.

34 Davidson LL, Durkin MS, Kuhn L, et al. The impact of the Safe Kids/Healthy Neighborhoods injury prevention program in Harlem, 1988 through 1991. Am F Public Health 1994;84:580-6.

35 Department of Health. Promoting better health - the government's programme for improving primary health care. London: HMSO, 1987. (CM249.)

36 Royal College of General Practitioners. The front line of the health service. London: RCGP, 1987.

37 Department of Health. The health of the nation. Key area handbooks: accidents. London: HMSO, 1993.

38 Coombes G. You can't watch them 24 hours a day. Parents' and children's perceptions, understanding and experiences of accidents and accident prevention. London: Child Accident Prevention Trust, 1991

39 Thomson R. Helping to prevent accidents in the home. Nursing Standard 1990;4:28-30.

40 Marsh GN, Russell D, Russell IT. What do health visitors contribute to the care of children? A study in the north of England. Fournal of the Royal College of General Practitioners 1989;39:201-5.

41 Lowe R. Preventing accidents to pre-school children: a health visitor's view. Public Health 1989;103:51-5.

42 MacInnes A. Accidents to pre-school children and the role of the health visitor. Health Visitor 1985;58:43-4.

43 Greig T. The GP's role in child accident prevention. Practitioner 1987;231:1612-16.

44 Rosser W, Feldman W, McGrath P. A critical look at the family physician's role in preventing childhood injuries. Can Fam Physician 1987;33:733-40.

45 Carter YH, Jones PW. General practitioners' beliefs about their role in the prevention and treatment of accidents involving children. Br f Gen Pract 1993;43:463-5.

46 Carter YH, Morgan PSA, Lancashire RJ. General practitioners' attitudes to child injury prevention in the UK: a national postal questionnaire. Inj Prev 1995;1:164-7.

47 Jackson RH. The doctor's role in the prevention of accidents. Arch Dis Child 1988;63:235-7.

48 Laidman P. Health visiting and preventing accidents to children. Research report 12. London: Health Education Authority, 1987.

49 Levene S. Accident prevention: the health visitor's role. Health Visitor 1992;65:340-41.

50 Levene S. Accident prevention: the nurse's role. Primary Health Care 1993;3:16-17.

51 Carter YH, Bannon MJ, Jones PW. The role of the teacher in child accident prevention. F Public Health Med 1994;16: 23-8.

52 Kendrick D. Role of the primary health care team in preventing accidents to children. Br f Gen Pract 1994;44 372-5.

53 Audit Commission. Seen but not heard. Co-ordinating community child health and social services for children in need. London: HMSO, 1994.

54 Hart JT. A new kind of doctor. London: Merlin Press, 1988.

55 Agass M, Mant D, Fuller A, et al. Childhood accidents: a practice survey using general practitioners' records and parental reports. Br f Gen Pract 1990;40:202-5. 
56 Towner EML. The role of health education in childhood

57 Child Accident Prevention Trust. Preventing accidents to children. A training resource for health visitors. London: Health Education Authority, 1991.

58 Cody A, Waine N. Preventing childhood accidents: an intervention exercise in Clwyd. British fournal of Nursing 1993 2:1059-64.

59 Phalp CGA. An assessment of the opportunities and needs of primary health care teams in London to undertake child accident prevention work. London: Child Accident Prevention Trust, 1995

60 Bass JL, Christoffel KK, Widome M, et al. Childhood injury prevention counseling in primary care settings: a critical review of the literature. Pediatrics 1993;92:544-50.

61 American Academy of Pediatrics Committee on Accident and Poison prevention. Implementing safety counselling in
office practice. Elk Grove Village, IL: American Academy of office practice. Elk
Pediatrics, 1990.
62 Bass JL, Mehta KA, Ostrovsky M, et al. Educating parents about injury prevention. Pediatr Clin North Am 1985;32: 233-42

63 Dorsch MM, Woodward AJ, Somers R. Do bicycle safety helmets reduce the severity of head injuries in real crashes? Accid Anal Prev 1987;19:183-90.

64 Thompson RS, Rivara FP, Thompson DC. A case-control study of the effectiveness of bicycle safety helmets. $N$ Engl f Med 1989;320:1361-7

65 Cameron MH, Vulcan AP, Finch CF, et al. Mandatory bicycle helmet use following a decade of helmet promotion in Victoria, Australia - an evaluation. Accid Anal Prev 1994; 26:325-37.

66 Lee A, Smyth J, Mann N. A bicycle helmet promotion campaign aimed to reduce head injuries in West Berkshire, 1992-1997. (Unpublished report.)

67 Kemp A, Gibbs N, Vafidis G, et al. Safe Child Penarth: experience with a Safe Community Strategies for preventexperience with a Safe Community Strategies
ing injuries to children. Inj Prev 1998;4:63-8. 